Revista Ambientale

Revista da Universidade Estadual de Alagoas/UNEAL

e-ISSN 2318-454X, Ano 13, Vol. 13 (3), 2021

https://doi.org/10.48180/ambientale.v13i3.305

\title{
Análise do comportamento social de cães (Canis lupus familiaris) domésticos em diferentes idades
}

Social behavior analysis of domestic dogs (Canis lupus familiaris) at different ages

\begin{abstract}
Mayara Karlla Rodrigues Lima ${ }^{1}$, Graduanda do Curso de Ciências Biológicas da Universidade Estadual de Alagoas - Campus I, E-mail: mayarakrlima99@ gmail.com, Eduardo dos Santos Silva², Graduanda do Curso de Ciências Biológicas da Universidade Estadual de Alagoas - Campus I, Email: eduardo.dudu18321s@ gmail.com, Geraldina Fernanda Ramos Fernanda ${ }^{3}$, Graduanda do Curso de Ciências Biológicas da Universidade Estadual de Alagoas - Campus I, E-mail:

fernandaramoa2@gmail.com
\end{abstract}

E-mail do autor correspondente: mayarakrlima99@gmail.com

Resumo - Seres psicologicamente bem desenvolvidos, os cães domesticados, com a ajuda do homem, provam todos os dias a capacidade de criar vínculos cheios de harmonia e sociabilidade, indo além do uso para ataque e caça, trazendo uma vida benéfica não só para o próprio animal, mas também para o dono. Dessa forma, objetivou-se com este trabalho analisar o comportamento animal através de um estudo de observação diária de cães, desde os primeiros meses de vida até os mais adultos, em situações de interação social com os proprietários, outros animais e o ambiente em que vivem, com a finalidade de entender melhor a convivência entre homem e animal de estimação e como ambos se adaptam ao dia-a-dia. Os animais, todos sem raça definida (também identificados pela sigla SRD), foram observados durante uma hora diariamente num período de um mês para uma coleta de dados mais aprofundada. Observouse que parte dos animais apresentam comportamentos específicos de interação mais evidentes do que outros, como ser mais sociável a outros cães e aos donos, mas ser averso ao gato da casa, e a importância do cuidado com o animal foi ressaltada, construindo um vínculo ainda maior nesta amizade. Concluiu-se, que os animais observados são bastante sociáveis, indicando que todas as interações são importantes para o crescimento e desenvolvimento dos cachorros, independentemente de sua raça.

Palavras-chave: etologia. interação homem-cão. bem-estar animal. 


\title{
Revista Ambientale
}

Revista da Universidade Estadual de Alagoas/UNEAL

e-ISSN 2318-454X, Ano 13, Vol. 13 (3), 2021

https://doi.org/10.48180/ambientale.v13i3.305

\begin{abstract}
Psychologically well-developed beings, domesticated dogs, with the help of man, prove every day their ability to create bonds full of harmony and sociability, going beyond their use for attack and hunting, bringing a beneficial life not only to the animal itself but also for the owner. Thus, the objective of this work was to analyze animal behavior through a study of daily observation of dogs from the first months of life to the most adult ones in situations of social interaction with owners, other animals and the environment in which live, with the purpose of better understanding the coexistence between man and pet and how both adapt to day-to-day life. The animals, all of no defined breed (also identified by the acronym SRD), were observed for one hour daily over a period of one month for further data collection. It was observed that some of the animals have specific interaction behaviors that are more evident than others, such as being more sociable to other dogs and owners, but being averse to the house cat, and the importance of caring for the animal was highlighted, building a even greater bond in this friendship. It was concluded that the animals observed are very sociable, indicating that all interactions are important for the growth and development of dogs, regardless of breed.
\end{abstract}

Keywords: socialization. human-dog interaction. animal welfare.

\section{Introdução}

$\mathrm{Na}$ biologia, para se estudar o comportamento é necessário leitura, pesquisa e análise de dados, estes adquiridos por experimentação, observação ou conhecimento de fatos; é o que diz Del-Claro (2004) quando aponta o estudo do Comportamento Animal como um grande exemplo, tendo as características básicas necessárias para o homem: alimentação, convivência em bando e adaptação para sobrevivência, sendo diretamente relacionadas a ciência especializada no "exercício da curiosidade humana na tentativa de compreensão da sua própria natureza animal", conhecida atualmente como etologia.

Segundo Teixeira e colaboradores (2018), a etologia teve início com Karl von Frisch, Konrad Lorenz e Nikolas Tinbergen, nos anos 1930 com o intuito de esclarecer aspectos do comportamento animal, levando em consideração as características evolutivas. O estudo do comportamento pode ser muito amplo, desde um único indivíduo até um grupo de animais da mesma espécie, além da análise em natureza ou em cativeiro, este onde boa parte das pesquisas é feita devido a facilidade e possibilidade do controle das variáveis (TEIXEIRA et. al, 2018)

Segundo Morell (2015) os cães (Canis lupus familiaris) foram os primeiros animais escolhidos pelo homem para ser domesticados, ocupando a posição mais alta de pets frequentes em lares. Eles são também aqueles que mais criam vínculos harmônicos com o grupo ou indivíduo no ambiente em que vivem, comunicativos e sociais (GARCIA et. al, 2012). Nos primeiros dias de vida, o filhote ainda não apresenta a coordenação motora totalmente desenvolvida, seus movimentos são fracos, mas curiosos, aprendendo a andar com suas quatro patas; é a partir dos três meses de vida que o comportamento canino é observado com mais precisão, pois é onde o animal estabelece um padrão para o caminho até a vida adulta (FARACO; SOARES, 2013).

Ainda segundo Faraco e Soares (2013), é após o terceiro mês que o filhote consegue identificar se o ambiente em que se encontra não trará qualquer ameaça à sua sobrevivência, 


\section{Revista Ambientale}

Revista da Universidade Estadual de Alagoas/UNEAL

e-ISSN 2318-454X, Ano 13, Vol. 13 (3), 2021

https://doi.org/10.48180/ambientale.v13i3.305

além de já poder se comunicar com demais animais da sua espécie, aprimorando suas habilidades naturais em sociedade, dessa forma sendo importante a definição de um treinamento ou, no mínimo, uma organização por meio do dono para o convívio do cão em sociedade.

De acordo com Garcia e colaboradores (2012), o sistema sensorial do filhote estará em desenvolvimento e a participação do treinamento é essencial para que o processo de identificação e habituação seja concluído, e o animal possa ser capaz de se adaptar e não apresentar sinais de agressividade, comportamento negativo natural do mamífero.

Por isso Bradshaw et. al (2009) recomenda um tratamento igualitário para todos os animais domesticados no ambiente, promovendo não apenas a interação entre os animais, mas também ao dono. Na literatura, há muitos estudos focados no comportamento em raças específicas, como visto em Jornada Científica dos Campos Gerais (2018) que os Shihtzu são animais sociais e interagem bem com pessoas, mas não diretamente analisando a mistura delas. Diante disso, o objetivo geral deste projeto foi entender melhor a convivência entre o homem e animal de estimação, especialmente cães sem raça definida (SRD), e como ambos aplicam a adaptação ao dia-a-dia.

\section{Material e métodos}

\section{Área de pesquisa}

A pesquisa foi realizada em propriedades privadas localizadas no município de Arapiraca e Girau do Ponciano, em Alagoas. Parte dos objetos de observação está situada no município pertencente à Mesorregião do Agreste Alagoano (Figura 1), enquanto a outra parte está situada em Girau do Ponciano (Figura 2).

Figura 1 - Localização do Estado de Alagoas no mapa do Brasil (canto inferior direito) e localização geográfica do município de Arapiraca (destaque em vermelho) dentro do Estado de Alagoas.

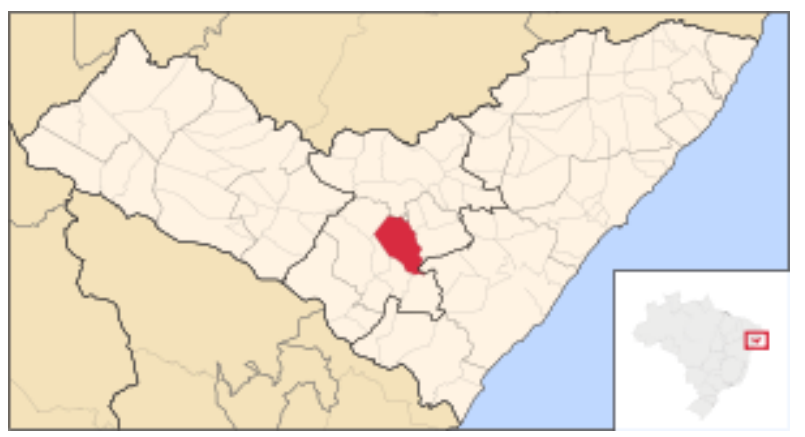

Fonte: Darlan P. de Campos, 2006. Dados da pesquisa. 
Revista Ambientale

Revista da Universidade Estadual de Alagoas/UNEAL

e-ISSN 2318-454X, Ano 13, Vol. 13 (3), 2021

https://doi.org/10.48180/ambientale.v13i3.305

Figura 2 - Localização do Estado de Alagoas no mapa do Brasil (em amarelo) e localização geográfica do município de Girau do Ponciano (destaque em vermelho) dentro do Estado de Alagoas.

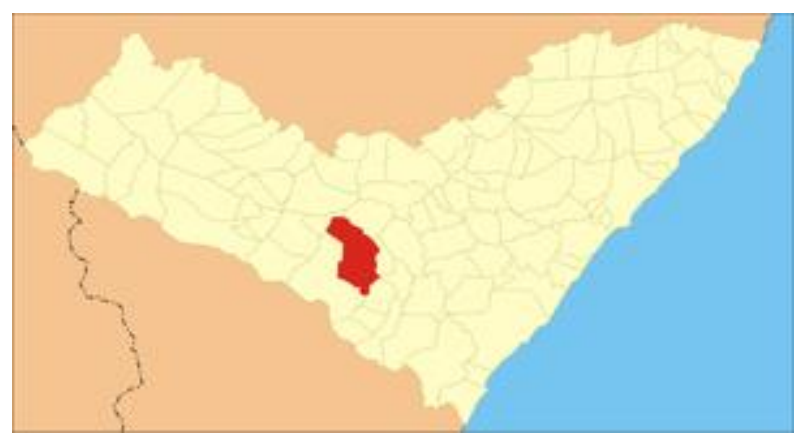

Fonte: Wellber Drayton, 2010. Dados da pesquisa.

\section{Aquisição dos cães}

Nenhum dos cães nasceu no ambiente em que se encontram atualmente, mas divergiram entre serem adotados com poucos meses de vida e já adultos (Figura 3), resgatando-os das ruas ou adquirindo-os por meio de terceiros. Todos os proprietários promoveram os cuidados necessários para a adaptação dos animais no ambiente em que se encontram atualmente.

Figura 3 - (A) Macho com 1 ano e 5 meses em zona rural. (B) Fêmea com 6 anos em zona urbana.
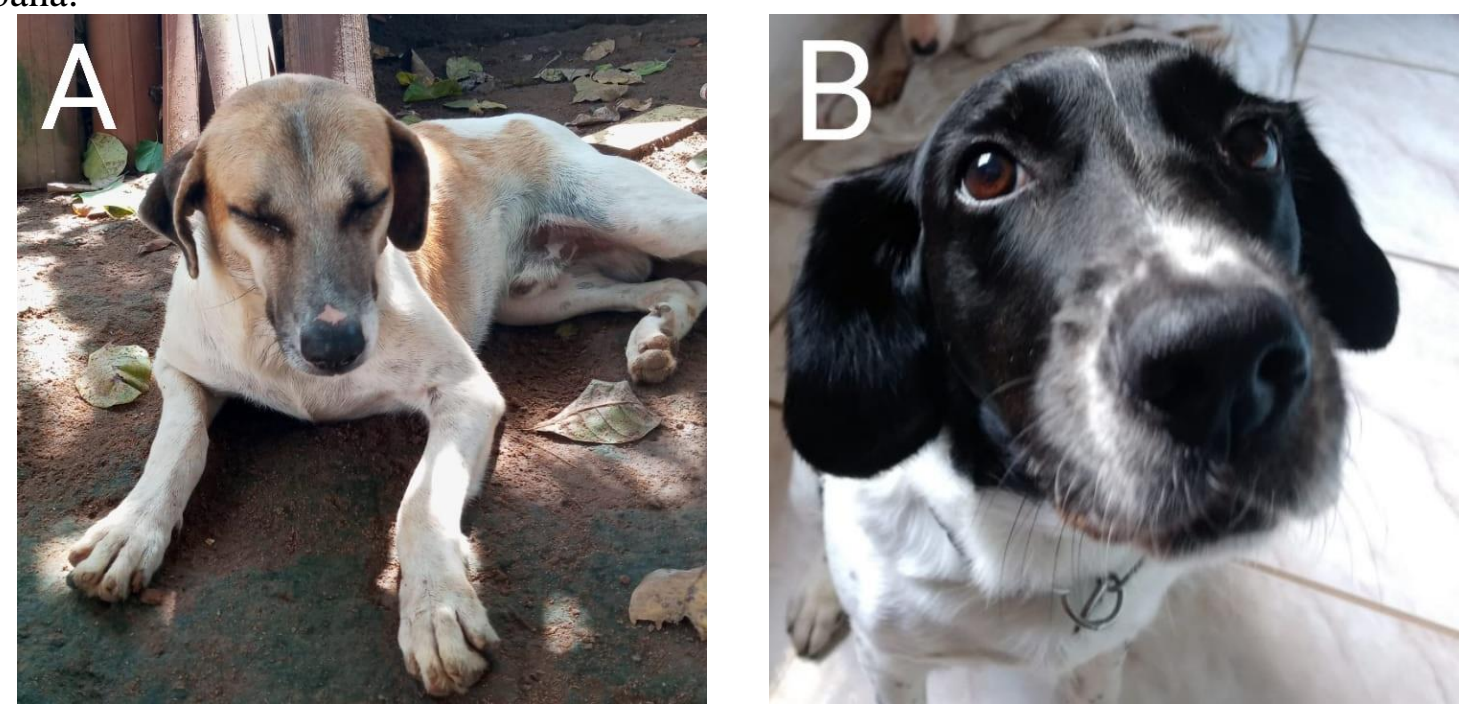

Fonte: dados da pesquisa. 


\section{Revista Ambientale}

Revista da Universidade Estadual de Alagoas/UNEAL

e-ISSN 2318-454X, Ano 13, Vol. 13 (3), 2021

https://doi.org/10.48180/ambientale.v13i3.305

\section{Organização das observações}

Foram analisados cães sem raça definida, variando entre machos e fêmeas, organizados em ordem de idade para melhor compreensão. As observações foram anotadas diariamente e em horários diferentes de acordo com a disponibilidade dos proprietários dos animais a serem analisados, aproximadamente uma hora para cada um. As informações mais relevantes para a pesquisa foram consideradas e divididas em tabelas para melhor entendimento e organização por parte dos alunos. Essas divisões foram feitas no seguinte padrão:

- Idade aproximada do animal: entre 1 a 3 meses, entre 4 a 6 meses, entre 7 meses a 1 ano, de 1 ano a mais;

- Sexo;

- Ambiente onde estão sendo mantidos;

- Comportamentos sociais positivos mais comuns: em relação a outros animais, à outras pessoas, aos donos.

Levando em consideração apenas a socialização positiva, a quantidade de cães que correspondem a cada comportamento foi distribuída nas tabelas.

\section{Resultados e discussão}

Durante a análise, os animais foram divididos em tabelas pelos sexos, fêmeas e machos, todos eles sem raça definida. Poucos cães foram coletados em Girau do Ponciano em relação aos de Arapiraca, mas não deixaram de ser analisados, abrindo espaço para uma segunda tabela (Tabela 2).

Tabela 1 - Análise completa sobre os cães escolhidos para a pesquisa em área urbana (Arapiraca).

\begin{tabular}{|c|c|c|c|c|c|}
\hline \multirow[t]{2}{*}{ IDADE } & \multirow{2}{*}{$\begin{array}{l}\text { SEXO } \\
\text { (M) }\end{array}$} & \multirow{2}{*}{$\begin{array}{l}\text { SEXO } \\
(\mathbf{F})\end{array}$} & \multicolumn{3}{|c|}{ COMPORTAMENTO SOCIAL POSITIVO COMUM } \\
\hline & & & $\begin{array}{c}\text { COM OUTROS } \\
\text { ANIMAIS }\end{array}$ & $\begin{array}{l}\text { COM OUTRAS } \\
\text { PESSOAS }\end{array}$ & $\begin{array}{c}\text { COM OS } \\
\text { PRÓPRIOS DONOS }\end{array}$ \\
\hline $\begin{array}{c}\text { Entre } 1 \text { a } 3 \\
\text { meses }\end{array}$ & 2 & 1 & 1 & 1 & 1 \\
\hline $\begin{array}{l}\text { Entre } 4 \text { a } 6 \\
\text { meses }\end{array}$ & 7 & 5 & 2 & 4 & 10 \\
\hline $\begin{array}{c}\text { Entre } 7 \\
\text { meses a } 1 \\
\text { ano }\end{array}$ & 10 & 4 & 5 & 5 & 14 \\
\hline
\end{tabular}


Revista Ambientale

Revista da Universidade Estadual de Alagoas/UNEAL

e-ISSN 2318-454X, Ano 13, Vol. 13 (3), 2021

https://doi.org/10.48180/ambientale.v13i3.305

\begin{tabular}{cccccc}
\hline $\begin{array}{c}\text { De } 1 \text { ano a } \\
\text { mais }\end{array}$ & 3 & 11 & 6 & 5 & 14 \\
\hline TOTAL & $\mathbf{2 2}$ & $\mathbf{2 1}$ & $\mathbf{4 3}$ & \\
\hline
\end{tabular}

Fonte: dados da pesquisa.

Apesar do curto período de avaliação, os resultados se mostraram mais detalhados do que visto em Jornada Científica dos Campos Gerais (2018), que apenas relatou o comportamento positivo de dois cachorros. Boa parte da análise declarou que os cães entre $4 \mathrm{e}$ 6 meses são mais positivos socialmente com seus donos, adaptando-se com as demais pessoas da casa e outros animais, assim como verificou Faraco e Soares (2013) que fala sobre a coordenação motora do animal formando-se a partir dos três meses de vida.

Enquanto o predomínio do comportamento social positivo é para com seus donos, a pequena parte menos sociável a outros animais e outras pessoas, segundo Rusky (2017), é explicada por inúmeros fatores, desde a mudança de humor durante o cio a os estímulos promovidos pelo ambiente.

Tabela 2 - Análise completa sobre os cães escolhidos para a pesquisa em área rural (Girau do Ponciano).

\begin{tabular}{cccccc}
\hline IDADE & $\begin{array}{c}\text { SEXO } \\
(\mathbf{M})\end{array}$ & $\begin{array}{c}\text { SEXO } \\
(\mathbf{F})\end{array}$ & \multicolumn{2}{c}{ COMPORTAMENTO SOCIAL POSITIVO COMUM } \\
\hline $\begin{array}{c}\text { Entre 1 a 3 } \\
\text { meses }\end{array}$ & 0 & 0 & 0 & 0 & 0 \\
\hline $\begin{array}{c}\text { Entre 4 a } 6 \\
\text { meses }\end{array}$ & 0 & 0 & 0 & 0 & 0 \\
\hline $\begin{array}{c}\text { Entre 7 } \\
\text { meses a 1 } \\
\text { ano }\end{array}$ & 0 & 2 & 0 & 2 & COMTROS OS \\
\hline $\begin{array}{c}\text { De 1 ano a } \\
\text { mais }\end{array}$ & 4 & 0 & 1 & 2 & 4 \\
\hline TOTAL & $\mathbf{4}$ & $\mathbf{3}$ & & 7 & \\
\hline
\end{tabular}

Fonte: Dados da pesquisa.

Em relação aos cães observados em Girau do Ponciano, mesmo com o número bem abaixo em comparação aqueles vistos em Arapiraca, os resultados coincidiram, reforçando a ideia de Rusky (2017) sobre os estímulos, não importando o ambiente em que se encontram, mas se houver amor e carinho, a relação será benéfica e mútua. 


\section{Conclusão}

Pode-se constatar que os cães são sim animais extremamente sociáveis, desde que seja fornecido comida, carinho, ambiente propício para seu desenvolvimento e atividades recreativas, indicando que a interação promovida pelo ser humano está sendo recompensada. Contudo, ainda há poucos estudos focados diretamente em comportamentos sociais específicos e em diferentes raças, por isso, sugere-se a realização destes estudos com a maior variação de comportamentos.

\section{Agradecimentos}

Agradeço ao Professor Dr. Rubens Pessoa de Barros, orientador desse estudo.

\section{Conflitos de interesse}

Os autores deste manuscrito não declararam conflitos de interesse. 


\section{Referências}

ABREU, R. L. Map of Alagoas state. 20 abr. 2006. Disponível em: https://commons.wikimedia.org/wiki/File:Alagoas_MesoMicroMunicip.svg Acesso em: 28 abr 2021.

BRADSHAW, J. W. S., BLACKWELL, E. J., CASEY R. A. Dominance in Domestic Dogs: Useful Construct or Bad Habit? J. Vet. Behav, 2009, n. 4, p. 135-144

DEL-CLARO, Kleber. Comportamento animal: uma introdução à ecologia comportamental. 1. ed. Jundiaí: Livraria e Editora Conceito, 2004. p. 132

DRAYTON, W. Localização da cidade de Alagoas. 17 Fev 2010. Disponível em: https://commons.wikimedia.org/wiki/File:Girau_do_Ponciano.png Acesso em: 28 abr 2021. FARACO, Ceres Berger; SOARES, Guilherme Marques. Fundamentos de comportamento canino e felino. 1. ed. São Paulo: Editora MedVet, 2013. p. 242

GARCIA, R. D. C. M; CALDERÓN, Nestor; FERREIRA, Fernando. Consolidação de diretrizes internacionais de manejo de populações caninas em áreas urbanas e proposta de indicadores para seu gerenciamento. Revista Panam Salud Publica, Washington, v. 32, n. 2, p. 140-144, jun./2012.

JORNADA CIENTÍFICA DOS CAMPOS GERAIS, 2018, Ponta Grossa. Anais [...]. Paraná: Jornada Científica dos Campos Gerais, 2018. v. 16.

MORELL, V. Evolução: do lobo ao cão. 13. ed. [S.l.]: SCIAM, 2015. p. 26-34 RUSKY, Renata. Macho ou fêmea? para evitar dores de cabeça, escolha bem o sexo do pet. [S. l.]: Correio Braziliense, 19 mar. 2017. Disponível em: https://www.correiobraziliense.com.br/app/noticia/revista/2017/03/19/interna_revista_correio ,581880/macho-ou-femea-para-evitar-dores-de-cabeca-escolha-bem-o-sexo-do-pet.shtml. Acesso em: 7 set. 2021.

TEIXEIRA, Camila Palhares; BARÇANTE, Luciana; AZEVEDO, C. S. D. Comportamento animal: uma introdução aos métodos e à ecologia comportamental. 1. ed. Curitiba: Appris Editora e Livraria Eireli, 2018. p. 7-8 